\title{
FDG PET/CT as a prognostic biomarker in the era of molecular-targeting therapies: max SUVmax predicts survival of patients with advanced renal cell carcinoma
}

Noboru Nakaigawa ${ }^{1 *}$, Keiichi Kondo ${ }^{1}$, Ukihide Tateishi², Ryogo Minamimoto², Tomohiro Kaneta², Kazuhiro Namura ${ }^{1}$, Daiki Ueno ${ }^{1}$, Kazuki Kobayashi ${ }^{3}$,Takeshi Kishida ${ }^{4}$, Ichiro Ikeda ${ }^{5}$, Hisashi Hasumi', Kazuhide Makiyama', Yoshinobu Kubota', Tomio Inoue ${ }^{2}$ and Masahiro Yao'

\begin{abstract}
Background: Various molecular-targeting therapies have become available for the treatment of advanced renal cell carcinoma (RCC). Accurate prognostication is desirable for choosing the appropriate treatment for individual patients. ${ }^{18}$ F-2-fluoro-2-deoxyglucose positron-emission tomography/computed tomography (FDG PET/CT) is a non-invasive tool for evaluating glucose accumulation, which can be an index of biological characteristics of cancer. We prospectively evaluated FDG PET/CT as a prognostic indicator in patients with advanced RCC.

Methods: A total of 101 patients slated for different systematic therapies for advanced RCC were enrolled between 2008 and 2014. A total of 61 patients had recurrent RCC (58 metastatic and 3 regional) and 40 patients had stage IV RCC (36 metastatic and 4 locoregional). Sixteen patients had not undergone nephrectomy. Pre-treatment FDG PET/CT was performed, and the max SUVmax (the highest SUV measurement in each patient) was recorded. The max SUVmax was compared with different clinical risk factors as prognostic indicators. The median observation period was 18 months (range 1-70 months).

Results: The max SUVmax of the 101 subjects ranged from undetectable to 23.0 (median 6.9). Patients with high max SUVmax had a poor prognosis. Multivariate analysis with standard risk factors revealed that max SUVmax was an independent predictor of survival ( $p<0.001$; hazard ratio 1.265; $95 \%$ confidence interval 1.159-1.380). A cutoff of 8.8 for max SUVmax advocated in our previous report was highly significant $(p<0.0001)$. When we subclassified the max SUVmax values, the median overall survival of subjects with max SUVmax $<7.0$ was 41.9 months. That of subjects with max SUVmax between 7.0 and 12.0 was 20.6 months. That of subjects with max SUVmax $\geq 12.0$ was 4.2 months. The differences were statistically significant.
\end{abstract}

Conclusions: Pretreatment max SUVmax assessed by FDG PET/CT is a useful prognostic marker for patients with advanced RCC, providing helpful information for clinical decision making.

Keywords: Renal cell carcinoma, Positron-emission tomography, Computed tomography, Prognosis, Targeted molecular therapy

\footnotetext{
* Correspondence: nakaigan@med.yokohama-cu.ac.jp

1 Department of Urology, Graduate School of Medicine, Yokohama City

University, 3-9 Fukuura, Kanazawa, Yokohama 236-0004, Japan

Full list of author information is available at the end of the article
} 


\section{Background}

Renal cell carcinoma (RCC) accounts for $3 \%$ of all adult cancers [1]. Approximately $30 \%$ of RCC patients are diagnosed with metastases, and an additional 20$40 \%$ develop metastases after radical nephrectomy with curative intent $[2,3]$. Cytokine therapies have been the only treatments available for advanced RCC for a long time, and have been associated with a disappointing outcome $[4,5]$. With elucidation of the oncogenic mechanisms of RCC, however, agents that target critical molecules in the biological pathways necessary for oncogenesis, such as vascular endothelial cell growth factor or the mammalian target of rapamycin (mTOR), have been developed. These molecular-targeting therapeutics have improved outcomes for patients with advanced RCC [6-9], and are recommended as the main treatments for advanced RCC in clinical guidelines applied worldwide $[10,11]$.

It is well known that prognoses for patients with RCC can vary, and the guidelines recommend risk-directed therapies using prognostic classifications based on a combination of clinical information and laboratory data $[8,10,11]$. The Memorial Sloan-Kettering Cancer Center (MSKCC) classification using five clinical factors including performance status, the interval from diagnosis to start of treatment, lactate dehydrogenase (LDH), corrected calcium, and anemia, is most commonly used for prognosis [12]. These clinical parameters are thought to express the biological activity of RCC indirectly. However, in this era of molecular-targeting therapy, an index that expresses the biological activity of RCC directly, and prognosticates accurately, is desired for appropriate clinical decision making.

${ }^{18} \mathrm{~F}$-2-fluoro-2-deoxyglucose positron emission tomography-computed tomography (FDG PET/CT) is a useful non-invasive tool for evaluating glucose metabolic status, which can be an index of the biological activity of cancer. We focused on standardized uptake value (SUV), a quantitative simplified measure of tissue FDG accumulation, and previously reported that max SUVmax (i.e., the highest SUV of all RCC lesions in each patient) predicted the overall survival (OS) of patients with advanced RCC [13]. In that paper, we reported that the survival of patients with max SUVmax greater than or less than the cutoff value of 8.8 were statistically different $(p=0.0012)$. Subsequently, Kayani reported that high SUVmax correlated with shorter overall survival in patients treated with the tyrosine kinase inhibitor (TKI) sunitinib [14]. Chen reported that baseline SUVmax correlated with the overall survival of patients with RCC treated by everolimus, which is an oral mTOR inhibitor (mTORI) [15]. Other investigators also advocated the usefulness of FDG PET/CT as a prognostic tool for patients with $\operatorname{RCC}[16,17]$.
In this study, we report results from an expanded number of patients and a longer follow-up period.

\section{Methods \\ Patients}

This was a prospective study that followed enrolled patients slated to undergo systemic therapies for pathologically proven advanced RCC between June 2008 and January 2014. The patients were initially assessed by conventional imaging techniques (computed tomography, magnetic resonance imaging, or bone scintigraphy) and diagnosed as stage IV or recurrent RCC. Patients with uncontrolled diabetes mellitus (fasting blood sugar $>$ $150 \mathrm{mg} / \mathrm{dL}$ ), other known malignancies, and patients who had received treatment within 2 weeks prior to enrollment were excluded. The study protocol was approved by the Yokohama City University Institutional Review Board. Written informed consent was obtained from all patients.

Initially, 110 patients were enrolled in the study. Nine were eventually eliminated: four whose pathology could not be confirmed conclusively, three who decided against treatment after evaluation by FDG PET/ CT, one patient had a fasting blood sugar over $150 \mathrm{mg} / \mathrm{dL}$, and one with contralateral kidney metastases for which accurate SUV could not be measured owing to the urinary excretion of the radiotracer. This left a total of 101 patients for the analysis, including 24 who had been analyzed in the preliminary report [12] The first therapeutic interventions after enrollment in this study were decided before the evaluation by FDG $\mathrm{PET} / \mathrm{CT}$.

\section{Imaging}

Patients fasted for at least $6 \mathrm{~h}$ prior to intravenous injection of ${ }^{18} \mathrm{~F}$ FDG. PET/CT images were acquired (Aquiduo $16^{\circ}$; Toshiba Medical Systems, Tokyo, Japan). One hour after injection of $2.5 \mathrm{MBq} / \mathrm{kg}$ of ${ }^{18} \mathrm{~F} \mathrm{FDG}$, $\mathrm{PET} / \mathrm{CT}$ images were acquired from the top of the head to the mid-thigh. A low-dose, non-contrast CT scan was acquired first and used for attenuation correction. Emission images were acquired in three-dimensional mode for 2 min per bed position. After PET acquisition, contrast-enhanced CT was performed with a 2-mm section thickness, $120 \mathrm{kV}, 400 \mathrm{~mA}, 0.5 \mathrm{~s} /$ tube rotation, from the top of the head to the mid-thigh, with breath holding. A total of $100 \mathrm{~mL}$ contrast medium (iopamidol) was administered intravenously at a rate of $1.0 \mathrm{~mL} / \mathrm{s}$. The scan delay was set at $120 \mathrm{~s}$ after the start of the injection of contrast material. Patients with serum creatinine levels $>1.5 \mathrm{mg} / \mathrm{dL}$ were examined without contrast material. The all cases with origin RCC were evaluated by contrast enhanced CT scan. Images were reconstructed by attenuation-weighted, ordered-subset expectation 
maximization (four iterations, 14 subsets, $128 \times 128$ matrix, with 5-mm Gaussian smoothing). The SUV was determined according to the standard formula, with activity in the volume of interest (VOI) recorded as $\mathrm{Bq}$ per $\mathrm{mL} /$ injected dose in $\mathrm{Bq}$ per total body weight $(\mathrm{kg})$. VOIs were positioned to encompass targets within areas of increased uptake and measured on each slice by two experienced physicians (DU and KM), who were blinded to clinical data. Discrepancies were resolved by consensus reading. Analysis of FDG uptake in the primary tumor was made with reference to contrast-enhanced CT

Table 1 Patients characteristics

\begin{tabular}{ll}
\hline Characteristic & No. of patients (\%) \\
\hline No. of patients & 101 \\
Sex & \\
$\quad$ Male & 83 \\
$\quad$ Female & 18
\end{tabular}

Age, years

Median (Range) 65

$(32-82)$

Pathology
Clear cell $\quad 86$

Papillary 6

Clear cell/Sarcomatoid 4

Sarcomatoid

Hemodialyssis

Unclassified

Prior nephrectomy

Yes

No

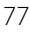

24

Disease status

Recurrent

Metastatic

Regional

Stage IV

Locoregional

Metastatic

61

58

3

40

4

36

Prior systematic Therapy

Yes

17

IFN-a

IFN-a/sorafenib

Sorafenib

Sunitinib

S-1

IFN-a/UFT

Sorafenib/Temsirolimus

No

84

(85)

(6)

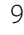

images to differentiate tumor from physiologic parenchymal and urinary tract activity. The maximum activity of all VOIs of each patient was defined as the max SUVmax.

\section{Statistical analysis}

Survival time was calculated from the date of evaluation by ${ }^{18} \mathrm{~F}$-FDG PET/CT to the date of death. A Cox proportional hazards model was used to assess the effects of max SUVmax on survival. OS curves were estimated by the Kaplan-Meier method, and the resulting curves were compared using the log-rank test. The impacts on overall survival (OS) of max SUVmax and other standard clinicopathologic factors (performance status, the interval from diagnosis to start of treatment, $\mathrm{LDH}$, corrected calcium, age, sex, and pathology) were analyzed by a univariate Cox hazard model, and the factors with $p<0.05$ were analyzed by a multivariate Cox hazard model. All statistical analyses were carried out with commercial software (SPSS ${ }^{\circ}$, SPSS Inc., Chicago, IL, USA).

\section{Results}

\section{Patient characteristics}

The characteristics of the 101 patients are shown in Table 1. Of 40 patients with Stage IV disease, 24 had not undergone prior nephrectomy. The FDG PET/CT evaluation of the 17 patients who had received prior therapy was performed more than 2 weeks after the end of any previous treatment.

Table 2 Interventions after PET/CT evaluation

\begin{tabular}{|c|c|c|c|}
\hline Interventions & No. of patients & & (\%) \\
\hline Single intervention & 44 & & (44) \\
\hline Sunitinib & & 19 & \\
\hline Sorafenib & & 20 & \\
\hline IFN-a & & 4 & \\
\hline Temsirolimus & & 1 & \\
\hline 2 interventions & 22 & & (22) \\
\hline TKI to mTORI & & 10 & \\
\hline TKI to TKI & & 9 & \\
\hline mTORI to TKI & & 3 & \\
\hline 3 interventions & 20 & & (20) \\
\hline $3<$ interventions & 15 & & (15) \\
\hline TKI & 96 & & (95) \\
\hline mTORI & 39 & & (39) \\
\hline IFN-a & 16 & & (16) \\
\hline Metastasectomy & 6 & & (6) \\
\hline Nephrectomy & 5 & & (5) \\
\hline
\end{tabular}

Abbrebiations: IFN- $a$ interferon- $a, T K I$ tyrosine kinase inhibitor, mTORI mTOR inhibitor 


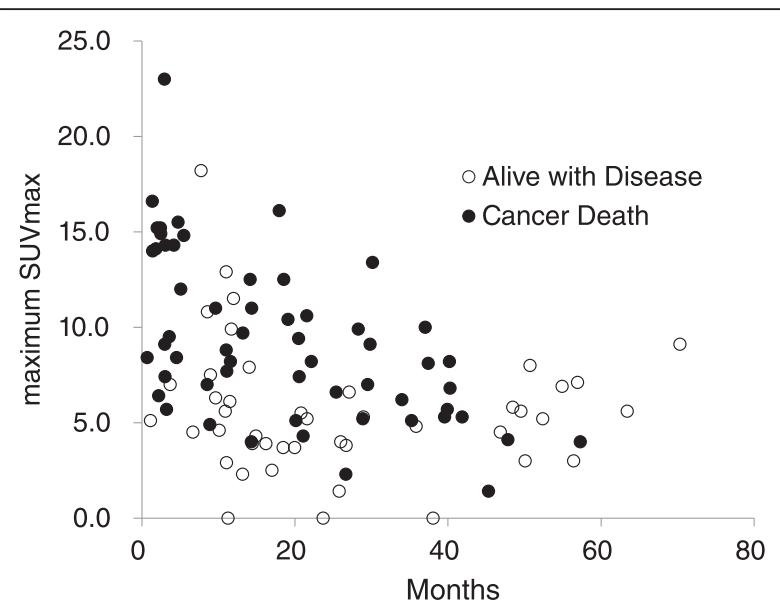

Fig. 1 The association of pretreatment max SUVmax and survival. The vertical axis plots the pretreatment max SUVmax of individual patients, and the horizontal axis plots their survival. Open circles are the patients who were alive on the last observation days and closed circles are the patients dead as a result of cancer

\section{Interventions}

After evaluation by PET/CT, 40 patients were treated with sorafenib, 38 with sunitinib, 12 with interferon- $\alpha$ (IFN- $\alpha$ ), eight with temsirolimus, one with axitinib, one with pazopanib, and one with chemotherapy. Comprehensive decisions regarding first interventions were made from pathological and clinical information before the FDG PET/CT evaluation.

The median observation period was 18 months (range $1-70)$. During the observation period, 44 patients were treated with a single intervention (20 sorafenib, 19 sunitinib, four IFN- $\alpha$, and one temsirolimus), 22 with two interventions (10 TKI to mTORI, 9 TKI to TKI, and 3 mTORI to TKI), 20 with three interventions, and 15 with more than three interventions. Ninety-six patients were treated with TKI, 43 with mTORI, and 16 with
IFN- $\alpha$. Six patients underwent metastasectomy, and five, nephrectomy (Table 2). There were 57 cases of death due to cancer; we confirmed that the other 44 patients were still alive at the time of this writing. There were no cases of death due to other causes.

\section{Assessment by FDG PET/CT}

The max SUVmax of all patients ranged from undetectable to 23.0 (median 6.9). When max SUVmax was analyzed as a continuous variable, high max SUVmax was associated with shorter OS, (Fig. 1) $(p<0.001$, hazard ratio 1.257, $95 \%$ confidence interval [CI] 1.177-1.342).

The impact of max SUVmax on OS was compared with that of numerous standard risk factors. The multivariate analysis of max SUVmax with performance status, LDH, corrected calcium, interval between diagnosis and entry, and pathology ( $p<0.05$ in univariate analysis) revealed that max SUVmax was a significant independent predictor of survival (Table 3).

At first, we validated the application of a cutoff of max SUVmax of 8.8, which was the same cutoff point for OS prediction used in our previous report [13], focusing on the 77 patients who were enrolled after the preliminary analysis. The median OS of the 52 patients with RCC having a max SUVmax $<8.8$ was 57.3 months, and that of the 25 patients with RCC having the max SUVmax $\geq$ 8.8 was 13.2 months (95\% CI 5.89-20.51) $(p<0.0001)$ (Fig. 2).

We then divided the 101 patients into three subgroups by max SUVmax. Because the existence of the subgroup of patients with RCC showing very high max SUVmax whose survival time were less than 1 year became apparent in Fig. 1. The max SUVmax of 51 patients (50\%) was $<7.0$ and the median OS of this subgroup was 41.9 months (95 \% CI 34.12-49.68). The max SUVmax of 32 patients (32\%) were $\geq 7.0$ and $<12.0$, and median OS was 20.6 months (95\% CI 12.4-28.8). The $\max$

Table 3 Univariate and multivariate Cox analyses of max SUVmax versus standard prognostic factors for advanced RCC

\begin{tabular}{|c|c|c|c|c|c|c|}
\hline \multirow[b]{2}{*}{ Risk Fcotr } & \multicolumn{3}{|c|}{ Univariate cox analyses } & \multicolumn{3}{|c|}{ Multivariate cox analyses } \\
\hline & $P$ value & $\mathrm{HR}$ & $95 \% \mathrm{Cl}$ & $P$ value & $\mathrm{HR}$ & $95 \% \mathrm{Cl}$ \\
\hline max SUVmax (continuous variable) & $<0.001$ & 1.257 & $1.177-1.342$ & $<0.001$ & 1.265 & $1.159-1.380$ \\
\hline Karnofsky performance status (<80 \%) & 0.036 & 2.107 & $1.051-4.221$ & 0.296 & 0.623 & $0.256-1.514$ \\
\hline $\begin{array}{l}\text { Lactate dehydrogenase } \\
\text { (>1.5x upper limit of normal) }\end{array}$ & $<0.001$ & 8.655 & $3.559-21.049$ & 0.001 & 5.026 & $1.935-13.052$ \\
\hline Corrected calcium (>10 mg/dl) & 0.014 & 2.457 & $1.198-5.038$ & 0.151 & 1.943 & $0.784-4.815$ \\
\hline Hemoglobin (<lower limit of normal) & 0.121 & 1.810 & $0.854-3.833$ & & & \\
\hline $\begin{array}{l}\text { Interval from initial diagnosis to } \\
\text { treatment ( }<1 \text { year) }\end{array}$ & 0.014 & 1.937 & $1.142-3.286$ & 0.164 & 1.549 & $0.836-2.870$ \\
\hline Age (>65 years old) & 0.416 & 0.803 & $0.474-1.361$ & & & \\
\hline Sex (male or female) & 0.890 & 1.046 & $0.551-1.984$ & & & \\
\hline Pathology (clear or non-clear) & 0.044 & 2.113 & $1.021-4.373$ & 0.962 & 0.980 & $0.419-2.291$ \\
\hline
\end{tabular}




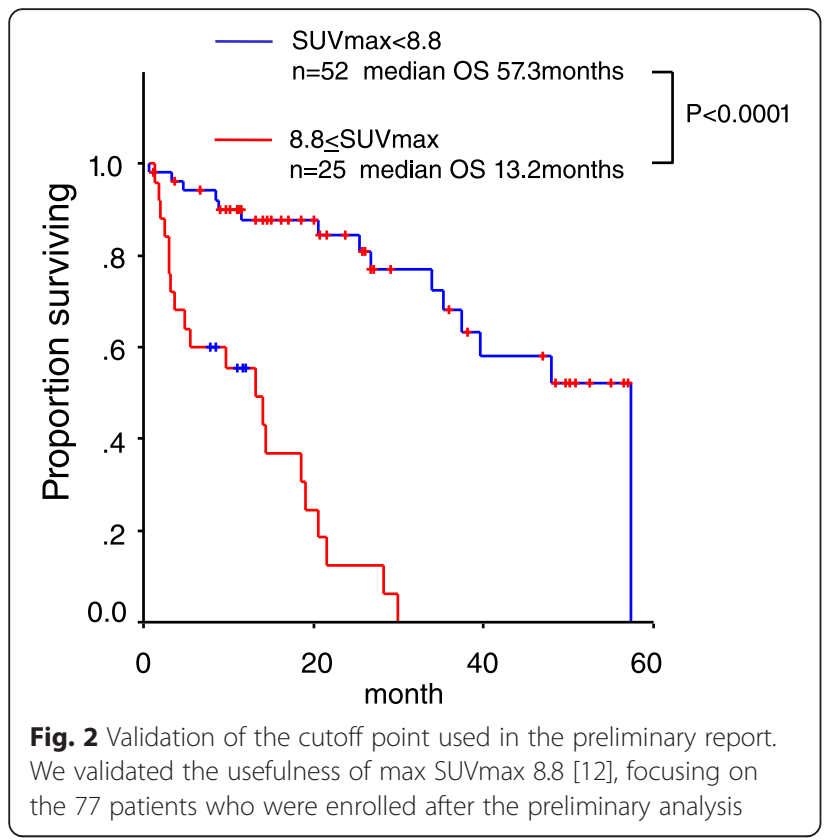

SUVmax of 18 patients (18\%) was $\geq 12.0$, and median OS was 4.2 months (95\% CI 0.7-7.7). Differences in OS for these patient subgroups were statistically significant $(<7.0$ vs. $\geq 7.0$ and $<12.0: p=0.0001, \geq 7.0$ and $<12.0$ vs. $\geq 12.0$ : $p=0.0004)$ (Fig. 3).

Figure 4 presents the features of the FDG PET/CT scans. Regardless of the tumor size and the organs where the metastasis was located, the patients with lower max SUVmax exhibited better OS than the patients with higher max SUVmax.

\section{Discussion}

We demonstrated that max SUVmax by FDG PET/CT is a useful prognostic marker for survival of patients with advanced RCC. It is reasonable that RCCs with high max SUVmax would have poorer prognoses because it has been suggested that RCCs with rapid progression need more glucose as an energy source and take up more FDG. Numerous recent studies of various types of cancer, including head-and-neck, lung, and cervical, have explored the prognostic significance of the SUV [18-21]. Although the size of our study was relatively small, the results were more significant compared with these studies of other malignancies. We propose two possible reasons for this result. The first is that the prognosis of patients with advanced RCC can vary widely. Many researchers have been trying to establish methods to predict the prognosis of RCC. The MSKCC classification advocated by Motzer et al. is most commonly used for prognosis [12], and they reported median OS of favorable, intermediate, and poor risk patients of 30,14, and 5 months, respectively, when the patients were divided into the three groups by five clinical risk factors. The second reason why results may have been more significant in our study was that the main treatments were targeted molecular therapeutics, which suppressed the biological activity of the cancer and the original biological properties of RCC affected the clinical courses markedly. We showed that the power of prediction by max SUVmax was superior to that by the risk factors used for MSKCC classification. It is meaningless, however, to discuss whether evaluation by FDG PET/CT or by clinical factors is better. We must focus on tailoring treatment according to prognosis to lengthen OS.

FDG PET/CT has not been generally applied to evaluate RCC owing to the urinary excretion of the radiotracer, which can mask the presence of primary lesions $[22,23]$. However we previously reported that FDG accumulation was evaluable in $94.9 \%$ of all RCC lesions diagnosed by a CT scan except for lung or liver metastases $<1 \mathrm{~cm}$, providing combined morphological and functional information [13]. These results were consistent with a previous report [24]. Additionally, Majhail et al. proved the pathological accuracy of diagnosis by FDG PET [25]. They

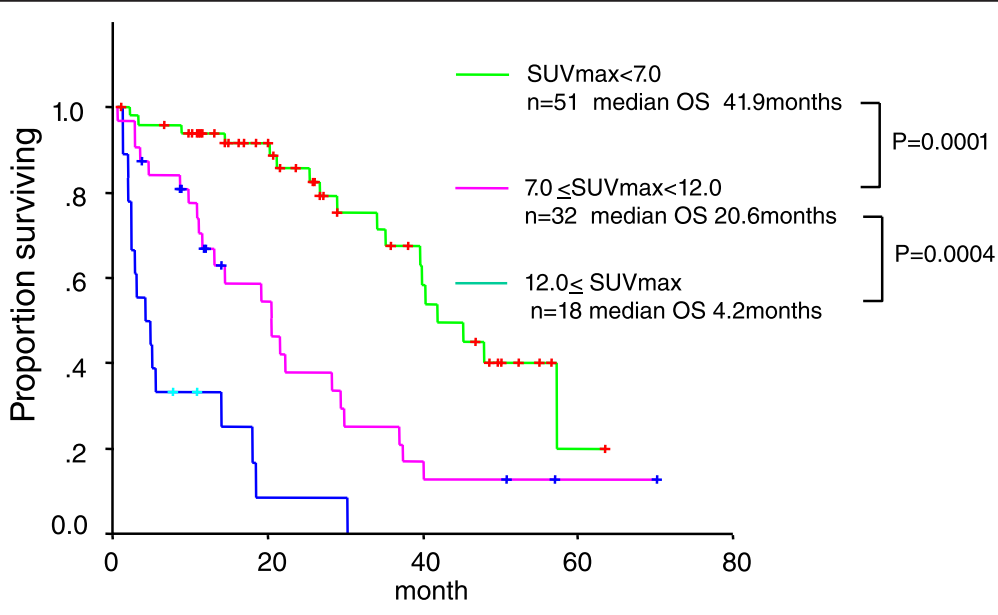

Fig. 3 Overall survival curve of total 101 patients stratified by two cutoff points, max SUVmax 7.0 and 12.0 


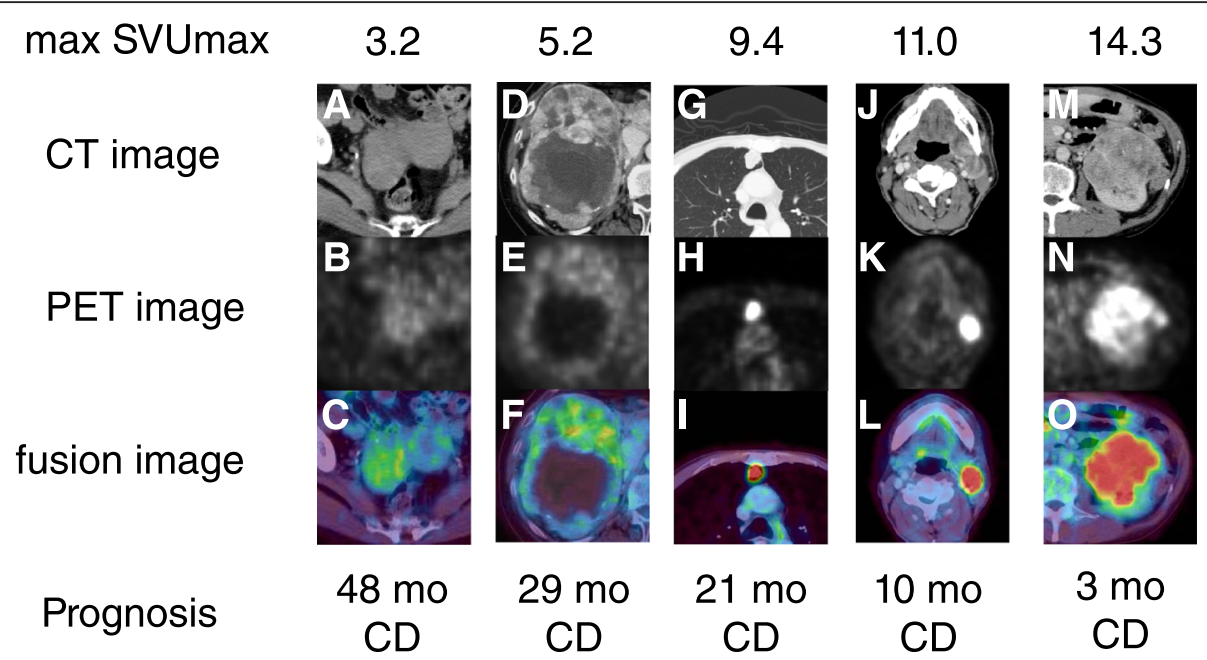

Fig. 4 The features of FDG PET/CT and prognosis. $(a, b, c)$ A case with ovarian recurrence and a max SUVmax of 3.2. $(d, e, f)$ A case with a primary tumor and a max SUVmax of 5.2. $(g, h, i)$ A case with lung metastasis and a max SUVmax of 9.4. $(j, k, l)$ A case with submandibular lymph node metastasis and a max SUVmax of 11.0. $(m, n, o)$ A case with a primary tumor and a max SUVmax of 14.3. a d g j m: CT imaging. $b$ e $h \mathrm{k} n$ : PET images. c f i / o: fusion images. mo=month. $C D=$ cancer death

performed biopsy or surgical resection of 36 distant metastatic lesions in 24 patients and revealed that the pathological positive predictive value of FDG PET/CT was $100 \%$.

Recently, we and other researchers have reported using FDG PET/CT to assess the response of RCC to molecular-targeting therapies [14, 26-28]. This evaluation is clinically beneficial because molecular-targeting therapies, as opposed to classical cytotoxic anticancer therapeutics, do not always cause obvious tumor shrinkage. These studies have reported that the decrease of FDG uptake predicted long-term dormancy of RCC, suggesting that FDG uptake can be used not just as a prognostic indicator before treatment, but also to assess the real-time status of biological activity in RCC. When more data about the assessment of RCC by FDG PET/ $\mathrm{CT}$ are accumulated in the future, the therapeutic strategy of the individual patient with advanced RCC may be decided based on the assessment by FDG PET/CT. For example, the patients with RCC showing very high max SUVmax will be treated with temsirolimus,, which is an intravenous mTOR inhibitor currently recommended for patients who are classified as "poor risk" by clinical risk factors. In contrast, patients with RCC showing low max SUVmax may be treated with more flexibility, focusing on the quality of life with the careful sequential assessment by FDG PET/CT.

Our study has several limitations. First, the patients were treated with various therapies, including TKI, mTORI, and IFN- $\alpha$ after evaluation by FDG PET/CT. Second, the number of systematic treatments that the patients enrolled in this study were subjected to were variable. Third, five patients underwent nephrectomies and six patients underwent metastasectomy, although the purpose of these surgeries was not complete resection.

The pretreatment max SUVmax assessed by FDG $\mathrm{PET} / \mathrm{CT}$ can predict survival of patients with advanced RCC. FDG PET/CT has the potential to provide helpful information for clinical decision making. Future pathological and molecular studies are needed to disclose the biological means of FDG accumulation in RCC.

\section{Conclusions}

Pretreatment max SUVmax assessed by FDG PET/CT can predict survival of patients with advanced RCC. FDG PET/ CT has the potential to be an "imaging biomarker," providing helpful information for clinical decision making.

\section{Abbreviations}

$\mathrm{Cl}$ : confidence interval; FDG PET/CT: ${ }^{18}$ F-2-fluoro-2-deoxyglucose positronemission tomography/computed tomography; IFN-a: interferon-a; LDH: lactate dehydrogenase; MSKCC: Memorial Sloan-Kettering Cancer Center; mTOR: mammalian target of rapamycin; mTORI: inhibitor of mammalian target of rapamycin; OS: overall survival; RCC: renal cell carcinoma;

SUV: standardized uptake value; TKI: tyrosine kinase inhibitor; VOI: volume of interest.

\section{Competing interests}

The authors declare that they have no competing interests.

\section{Authors' contribution}

NN had full access to all of the data in the study and takes responsibility for the integrity of the data and the accuracy of the data analysis. All authors read and approved the final manuscript. Study concept and design: NN. Acquisition of data: KeKo, KaKo, TaKi, II, HH, KM. Analysis and interpretation of data: UT, RM, ToKa, KN, DU. Administrative, technical, or material support: NN, YK, TI, MY. Drafting of the manuscript: NN. Critical revision of the manuscript for important intellectual content: MY. Obtaining funding and supervision: NN. 


\section{Acknowledgments}

This works was supported in part by Grants-in-Aid for Scientific Research (Nos. 22591775, and 25462494) from the Ministry of Education, Culture, Sports, Science and Technology of Japan.

The following list represents contributors involved in this study (in alphabetical order): Hayashi N, Kitami K, Miura T, Murakami T, Muraoka K, Noguchi K, Ohgo Y, Sano F, Takizawa A, Tsuchiya F, and Umemoto S.

\section{Author details}

'Department of Urology, Graduate School of Medicine, Yokohama City University, 3-9 Fukuura, Kanazawa, Yokohama 236-0004, Japan. ²Department of Radiology, Yokohama City University Graduate School of Medicine, Yokohama, Japan. ${ }^{3}$ Department of Urology, Yokosuka Kyosai Hospital Yokosuka, Japan. ${ }^{4}$ Department of Urology, Kanagawa Cancer Center, Yokohama, Japan. ${ }^{5}$ Department of Urology, Yokohama Minami Kyosai Hospital, Yokohama, Japan.

Received: 15 February 2015 Accepted: 28 January 2016

Published online: 08 February 2016

\section{References}

1. Chow WH, Devesa SS, Warren JL, Fraumeni Jr JF. Rising incidence of renal cell carcinoma in the United States. JAMA. 1999;281:1628-31.

2. Linehan WM, Walther MM, Alexander RB, Rosenberg SA. Adoptive immunotherapy of renal cell carcinoma.: studies from the Surgery Branch, National Cancer Institute. Semin Urol. 1993;11:41-3.

3. Janzen NK, Kim HL, Figlin RA, Belldegrun AS. Surveillance after radical or partial nephrectomy for localized renal cell carcinoma and management of recurrent disease. Urol ClinNorth Am. 2003:30:843-52.

4. Motzer RJ, Bander NH, Nanus DM. Renal-cell carcinoma. N Engl J Med. 1996; 335:865-75

5. Negrier S, Escudier B, Lasset C, Douillard JY, Savary J, Chevreau C, et al. Recombinant human interleukin-2, recombinant human interferon alfa-2a, or both in metastatic renal cell carcinoma: Groupe Français D'Immunotherapie. N Engl J Med. 1998;338:1272-8.

6. Motzer RJ, Hutson TE, Tomczak P, Michaelson MD, Bukowski RM, Rixe O, et al. Sunitinib versus interferon alfa in metastatic renal cell carcinoma. $\mathrm{N}$ Engl J Med. 2007;356:115-24.

7. Escudier B, Eisen T, Stadler WM, Szczylik C, Oudard S, Siebels M, et al. Sorafenib in advanced clear cell renal cell carcinoma. N Engl J Med. 2007; 356:125-34.

8. Hudes G, Carducci M, Tomczak P, Dutcher J, Figlin R, Kapoor A, et al. Temsirolimus, interferon alfa, or both for advanced renal-cell carcinoma. N Engl J Med. 2007;356:2271-81.

9. Motzer RJ, Escudier B, Oudard S, Hutson TE, Porta C, Bracarda S, et al. Efficacy of everolimus in advanced renal cell carcinoma: a double-blind, randomised, placebo-controlled phase III trial. Lancet. 2008;372:449-56.

10. European Association of Urology: European Association of Urology guidelines 2014 edition. 2014, Available at: http://uroweb.org/guideline/ renal-cell-carcinoma/.

11. National Comprehensive Cancer Network: NCCN Clinical Practice Guideline in Oncology: Kidney Cancer V.1. 2015. 2015, Available at: http://www.nccn. org/professionals/physician_gls/f_guidelines.asp\#site

12. Motzer RJ, Bacik J, Murphy BA, Russo P, Mazumdar M. Interferon-alfa as a comparative treatment for clinical trials of new therapies against advanced renal cell carcinoma. J Clin Oncol. 2002;20:289-96.

13. Namura K, Minamimoto R, Yao M, Makiyama K, Murakami T, Sano F, et al. Impact of maximum standardized uptake value (SUVmax) evaluated by 18-fluoro-2-deoxy-D-glucose positron emission tomography/computed tomography (18 F-FDG-PET/CT) on survival for patients with advanced renal cell carcinoma: a preliminary report. BMC Cancer. 2010;10:667.

14. Kayani I, Avril N, Bomanji J, Chowdhury S, Rockall A, Sahdev A, et al. Sequential FDG-PET/CT as a biomarker of response to Sunitinib in metastatic clear cell renal cancer. Clin Cancer Res. 2011;17:6021-8.

15. Chen JL, Appelbaum DE, Kocherginsky M, Cowey CL, Rathmell WK, McDermott DF, et al. FDG-PET as a predictive biomarker for therapy with everolimus in metastatic renal cell cancer. Cancer Med. 2013:2:545-52.

16. Ferda J, Ferdova E, Hora M, Hes O, Finek J, Topolcan O, et al. 18 F-FDG-PET/ $C T$ in potentially advanced renal cell carcinoma: a role in treatment decisions and prognosis estimation. Anticancer Res. 2013;33:2665-72.
17. Mizuno T, Kamai T, Abe H, Sakamoto S, Kitajima K, Nishihara D, et al. Clinically significant association between the maximum standardized uptake value on 18 F-FDG PET and expression of phosphorylated Akt and S6 kinase for prediction of the biological characteristics of renal cell cancer. BMC Cancer. 2015;15:1097.

18. Allal AS, Slosman DO, Kebdani T, Allaoua M, Lehmann W, Dulguerov P. Prediction of outcome in head-and-neck cancer patients using the standardized uptake value of 2-[18 F]fluoro-2-deoxy-D-glucose. Int J Radiat Oncol Biol Phys. 2004;59:1295-300.

19. Downey RJ, Akhurst T, Gonen M, Vincent A, Bains MS, Larson S, et al. Preoperative F-18 fluorodeoxyglucose-positron emission tomography maximal standardized uptake value predicts survival after lung cancer resection. J Clin Oncol. 2004;22:3255-60.

20. Sasaki R, Komaki R, Macapinlac H, Erasmus J, Allen P, Forster K, et al. [18 F] fluorodeoxyglucose uptake by positron emission tomography predicts outcome of non-small-cell lung cancer. J Clin Oncol. 2005;23:1136-43.

21. Lee $Y Y$, Choi $\mathrm{CH}$, Kim CJ, Kang H, Kim TJ, Lee JW, et al. The prognostic significance of the SUVmax (maximum standardized uptake value for F-18 fluorodeoxyglucose) of the cervical tumor in PET imaging for early cervical cancer: preliminary results. Gynecol Oncol. 2009;115:65-8.

22. Aide N, Cappele O, Bottet P, Bensadoun H, Regeasse A, Comoz F, et al. Efficiency of [(18)F]FDG PET in characterising renal cancer and detecting distant metastases: a comparison with CT. Eur J Nucl Med Mol Imaging. 2003:30:1236-45.

23. Kang DE, White Jr RL, Zuger JH, Sasser HC, Teigland CM. Clinical use of fluorodeoxyglucose $F 18$ positron emission tomography for detection of renal cell carcinoma. J Urol. 2004;171:1806-9.

24. Park JW, Jo MK, Lee HM. Significance of 18 F-fluorodeoxyglucose positronemission tomography/computed tomography for the postoperative surveillance of advanced renal cell carcinoma. BJU Int. 2009;103:615-9.

25. Majhail NS, Urbain JL, Albani JM, Kanvinde MH, Rice TW, Novick AC, et al. F-18 fluorodeoxyglucose positron emission tomography in the evaluation of distant metastases from renal cell carcinoma. J Clin Oncol. 2003;21:3995-4000

26. Lyrdal D, Boijsen M, Suurküla M, Lundstam S, Stierner U. Evaluation of sorafenib treatment in metastatic renal cell carcinoma with 2-fluoro-2deoxyglucose positron emission tomography and computed tomography. Nucl Med Commun. 2009;30:519-24.

27. Vercellino L, Bousquet $G$, Baillet $G$, Barré E, Mathieu O, Just PA, et al. 18 F-FDG PET/CT imaging for an early assessment of response to sunitinib in metastatic renal carcinoma: preliminary study. Cancer Biother Radiopharm. 2009:24:137-44.

28. Ueno D, Yao M, Tateishi U, Minamioto R, Makiyama K, Hayashi N, et al. Early assessment by FDG-PET/CT of patients with advanced renal cell carcinoma treated with tyrosine kinase inhibitors is predictive of disease course. BMC Cancer. 2012;12:162

\section{Submit your next manuscript to BioMed Central and we will help you at every step:}

- We accept pre-submission inquiries

- Our selector tool helps you to find the most relevant journal

- We provide round the clock customer support

- Convenient online submission

- Thorough peer review

- Inclusion in PubMed and all major indexing services

- Maximum visibility for your research

Submit your manuscript at www.biomedcentral.com/submit
) Biomed Central 